\title{
A survey of phenotype II in familial Mediterranean fever
}

Melike Melikoğlu, Huri Özdoğan, Cengiz Korkmaz, Özgür Kasapçopur, Nil Arısoy, Semra Akkuş, Izzet Fresko, Hasan Yazıcı

\begin{abstract}
Objective-Phenotype II in familial Mediterranean fever (FMF) is the onset of amyloidosis before the onset of FMF with its typical attacks, or as an isolated finding in a member of an FMF family. Its presence was investigated by looking for proteinuria among the asymptomatic relatives of patients with FMF complicated by amyloidosis and among the asymptomatic relatives of patients with juvenile chronic arthritis (JCA) complicated by amyloidosis, used as controls.

Methods-The relatives of the index patients (13 with FMF and amyloidosis) and controls (6 with JCA and amyloidosis) were screened for proteinuria. Rectal biopsies were performed when proteinuria was significant ( $\geqslant 300 \mathrm{mg} / \mathrm{d})$.

Results-461 relatives were screened in the FMF group and 269 among the controls. Two of the FMF relatives and one JCA relative had no symptoms of FMF but had significant proteinuria. Rectal biopsy for amyloidosis was negative in all instances of significant proteinuria.

Conclusion-Phenotype II is uncommon among the relatives of patients with FMF and amyloidosis.
\end{abstract}

(Ann Rheum Dis 2000;59:910-913)

Department of

Cerrahpașa Medical

School, University of Istanbul, Istanbul,

Turkey

M Melikoğlu

H Özdoğan

İ Fresko

H Yazıc1

Department of Internal Medicine, Osmangazi Medical School, University of Eskişehir, Eskişehir, Turkey

C Korkmaz

Department of Paediatrics,

Cerrahpașa Medical

School

Ö Kasapçopur

N Arisoy

S Akkuş

Correspondence to:

Dr Huri Özdoğan, Kașaneler

sok $2 / 5$, Erenköy, Istanbul

81060, Turkey

ozdogan@attglobal.net

Accepted for publication 10 April 2000
Table 2 Clinical features of the six patients with juvenile chronic arthrits and amyloidosis

\begin{tabular}{lllllll}
\hline & 1 & 2 & 3 & 4 & 5 & 6 \\
\hline Age & 19 & 15 & 22 & 24 & 19 & 7 \\
Sex & F & M & M & M & F & M \\
Disease duration (years) & 15 & 8 & 16 & 13 & 12 & 5 \\
$\begin{array}{l}\text { Duration of amyloidosis } \\
\text { (years) }\end{array}$ & 2 & 6 & 9 & 1 & 5 & 1 \\
Alive (+/-) & - & - & + & - & + & - \\
\hline
\end{tabular}

Phenotype II is a clinical observation that has not yet been considered formally. ${ }^{5}$ Because the presence of permanent proteinuria is usually the first laboratory finding in AA amyloidosis, we screened the family members of patients with typical FMF and amyloidosis for proteinuria. We also screened the relatives of patients with juvenile chronic arthritis (JCA) and amyloidosis as a control group. The initial screening test for amyloidosis was the presence of significant proteinuria ( $\geqslant 300 \mathrm{mg} / 24 \mathrm{~h}$ ). If this was present, a rectal biopsy was done.

Materials and methods

The index patients of our survey were 13 patients with classic FMF and amyloidosis (phenotype I) and six patients with JCA and amyloidosis, all with nephrotic syndrome. Amyloidosis was histologically proved in all index cases. We screened the relatives of the index patients up to the third generation by house visits. They were questioned for a history of recurrent attacks of fever, abdominal and/or pleural pain, arthritis (localised to hip, knee, ankle), skin rash, appendicitis, and renal disease by a standard questionnaire. The diagnosis of FMF among the family members of the index cases was made according to the manifestations listed above. If a relative had died, the cause of death was determined in detail, with particular interest in a renal cause. During the house visits, each relative was asked for a urine specimen to be tested for protein by reagent strips (Multistix 10 SG; Bayer Corp, USA). If the result was positive, a 24 hour urinary specimen was obtained. If proteinuria exceeded $300 \mathrm{mg} / 24 \mathrm{~h}$, the family member was referred to the rheumatology unit in Cerrah-

\begin{tabular}{llllllllllllll} 
Table 1 & Clinical features of the & 13 & index patients with familial Mediterranean fever and amyloidosis \\
\hline & 1 & 2 & 3 & 4 & 5 & 6 & 7 & 8 & 9 & 10 & 11 & 12 & 13 \\
\hline Age & 25 & 45 & 42 & 34 & 20 & 22 & 23 & 17 & 12 & 15 & 13 & 16 & 15 \\
Sex & $\mathrm{F}$ & $\mathrm{M}$ & $\mathrm{M}$ & $\mathrm{M}$ & $\mathrm{M}$ & $\mathrm{F}$ & $\mathrm{F}$ & $\mathrm{M}$ & $\mathrm{F}$ & $\mathrm{F}$ & $\mathrm{F}$ & $\mathrm{F}$ & $\mathrm{F}$ \\
Disease duration (years) & 21 & 43 & 40 & 29 & 14 & 19 & 17 & 9 & 8 & 10 & 9 & 7 & 13 \\
Duration of amyloidosis (years) & 1 & 6 & 12 & 2 & 2 & 11 & 6 & 2 & 5 & 1 & 4 & 3 & 4 \\
Alive (+/-) & + & + & + & + & + & + & + & - & + & + & + & + \\
\hline
\end{tabular}


Table 3 The distribution of the cases with familial Mediterranean fever (FMF) among the screened relatives of the index patients with FMF and amyloidosis

\begin{tabular}{|c|c|c|c|c|c|c|c|c|c|c|c|c|c|c|c|}
\hline & \multicolumn{13}{|c|}{ Patient No } & \multirow{2}{*}{$\begin{array}{l}\text { Relatives } \\
(n)\end{array}$} & \multirow{2}{*}{$\begin{array}{l}F M F(N o \\
(\%))\end{array}$} \\
\hline & 1 & 2 & 3 & 4 & 5 & 6 & 7 & 8 & 9 & 10 & 11 & 12 & 13 & & \\
\hline 1st degree ${ }^{\star}$ & 2 & 1 & 1 & 1 & - & - & - & 1 & - & - & 1 & 1 & 1 & 63 & $9(14)$ \\
\hline 2nd degree $\dagger$ & - & - & 1 & - & - & - & 1 & 1 & 1 & - & 3 & & - & 123 & $7(6)$ \\
\hline 3rd degree $\neq$ & 1 & 1 & 1 & 1 & - & - & 1 & 4 & - & - & 2 & - & 2 & 223 & $13(6)$ \\
\hline 4th degree & 1 & 2 & 1 & - & & & & 1 & - & - & - & & & 52 & $5(10)$ \\
\hline Total number & 4 & 4 & 4 & 2 & 0 & 0 & 2 & 7 & 1 & 0 & 6 & 1 & 3 & 461 & $34(7)$ \\
\hline
\end{tabular}

* 1 st degree: parents, sibs, and offspring of the proband. In our sample there were only parents or sibs.

$\dagger 2$ nd degree: grandparents, uncles/aunts, nieces/nephews, grandchildren. In our sample there were only uncles aunts, and nephews. $\ddagger 3$ rd degree: first cousins as all 3rd degree relatives were in our sample.

ๆ 4 th degree: first cousins once removed as all 4 th degree relatives were in our sample.

paşa Medical School in Istanbul, for a rectal biopsy. The specimens were stained with Congo red and were defined as positive for amyloidosis if they gave a green birefringence under polarising microscopy. The presence of AA amyloidosis was confirmed by the potassium permanganate method.

\section{Results}

All patients with FMF, including the index cases, fulfilled Tel Hashomer criteria. ${ }^{11}$ A total of 574 relatives for the FMF group and 303 for the JCA group were potentially available for screening. We were able to visit 461 family members of the index cases with FMF (80\%) and $269(89 \%)$ of the index cases with JCA in nine different cities in Turkey. A mean of 38 members (range 18-71) were questioned for each family. The age at which amyloidosis was detected in the 13 patients with FMF ranged from 7 to 39 years (median age 15). Tables 1 and 2 show the clinical features of the index cases with FMF and JCA, respectively.

FMF AMONG THE FAMILY MEMBERS OF THE FMF AND JCA INDEX PATIENTS

FMF was suspected in 56 family members of 461 screened (12\%), but the diagnosis was definite in $34(7 \%)$. Probable cases consisted of 22 subjects who had attacks lasting less than 12 hours or more than one week, arthritis localised to the joints other than the specified localisations (like hips, ankles or knees), or probable serosal attacks limited to restricted areas. Eight of the 34 definite cases had previously been diagnosed as FMF.

A total of 34 brothers or sisters of the index patients were interviewed. Of these, seven had FMF, each connected with a different index

Table 4 Distribution of proteinuria and amyloidosis among the index cases and controls

\begin{tabular}{|c|c|c|c|c|}
\hline & No (\%) & $\begin{array}{l}\text { Proteinuria } \geqslant 300 \\
m g / 24 h(n)\end{array}$ & Rectal biopsy (n) & Amyloidosis (n) \\
\hline FMF $\ddagger$ family & 461 & 7 & 4 & 1 \\
\hline $\mathrm{FMF}(+)$ & $34(7)$ & $5^{\star}$ & 2 & 1 \\
\hline FMF (-) & $427(93)$ & $2 \dagger$ & 2 & 0 \\
\hline JCA $\ddagger$ family & 269 & 1 & 1 & 0 \\
\hline $\mathrm{FMF}(+)$ & $2(0.7)$ & 0 & 0 & 0 \\
\hline FMF $(-)$ & $267(99)$ & $1 \dagger$ & 1 & 0 \\
\hline Total & 730 & 8 & 5 & 1 \\
\hline
\end{tabular}

^FMF phenotype I.

†Probable FMF phenotype II.

$\ddagger \mathrm{FMF}=$ familial Mediterranean fever; JCA = juvenile chronic arthritis. patient. In two families two generations were affected. One index case had a father and the other had sister and a mother with FMF. Table 3 shows the distribution of FMF cases among the FMF families according to the degree of relatives. There was no apparent consanguinity among the parents of these subjects and they had come from different geographical areas. Two family members with probable FMF had died because of renal failure.

Among the 269 relatives of the JCA group, only two patients $(0.7 \%)$ with FMF, belonging to the family of a single index patient, were found-a sister and a paternal cousin. The index case was a patient of ours with polyarticular JCA and probable abdominal attacks of FMF who had died of renal insufficiency due to amyloidosis. The sister with polyarticular JCA, had recurrent abdominal attacks along with chronic arthritis. Her abdominal attacks, but not her arthritis, responded to colchicine treatment. The other relative was a paternal cousin, with recurrent episodes of arthritis without a previous diagnosis of FMF.

PROTEINURIA AMONG THE FAMILY MEMBERS OF THE FMF AND JCA INDEX PATIENTS

Table 4 shows the distribution of proteinuria and amyloidosis among the index cases and controls. In 41 of the 730 urine specimens tested the Multistix test was positive for the presence of protein. Proteinuria $>300 \mathrm{mg} / 24 \mathrm{~h}$ was found in seven members of the FMF group. None of the subjects with probable FMF had proteinuria. Five of the seven subjects had a typical history of FMF attacks, whereas two had no history of attacks of FMF. AA amyloidosis was diagnosed in one of the two patients from the group of five symptomatic patients who agreed to undergo rectal biopsy. Rectal biopsy was negative for amyloidosis in both of the asymptomatic patients. One was a 48 year old woman, with a proteinuria of $500 \mathrm{mg} / 24 \mathrm{~h}$, with normal physical and laboratory examination. Proteinuria was not sustained on subsequent examinations. The other patient was a 56 year old woman with an uncontrolled hypertension of 10 years. She had $1 \mathrm{~g} / \mathrm{d}$ of proteinuria which, we thought, went together with hypercholesterolaemia, hypertensive retinopathy, and a mildly decreased renal function (creatinine clearance $70 \mathrm{ml} / \mathrm{min}$ ). 
The patient from the JCA group with significant proteinuria was an 11 year old girl who belonged to the family which had two members with FMF. The proteinuria was $500 \mathrm{mg} / 24 \mathrm{~h}$. She had no sign of amyloidosis at rectal biopsy.

Renal biopsy could not be performed in any of these three patients.

\section{Discussion}

The concept of phenotype II in FMF has been built on various case reports ${ }^{16-8}$ and on one large series from Turkey as reported in two publications. ${ }^{9}{ }^{10}$ The reported incidence ranges from $7 \%^{1}$ to $25 \%$ of $\mathrm{FMF}$ patients with amyloidosis. $^{910}$ Eight cases of phenotype II were reported in the seminal article by Sohar et $a l .{ }^{1}$ In five, the typical disease attacks became apparent approximately two years after the onset of renal amyloidosis. The remaining three patients failed to develop any symptoms of FMF. Another report described three patients with equivocal features. ${ }^{6}$ One patient who was reported to have had the phenotype II, had a positive family history, a history of osteomyelitis, and vague episodes of abdominal pain. This patient had a one year history of fever and diffuse pain; all symptoms which are quite unusual for typical FMF. Another patient who belonged to a family with FMF and amyloidosis, had transient proteinuria without a histopathological diagnosis.

The largest case series reported to have the phenotype II was from Turkey. Sixty per cent of the cases with FMF from a paediatric nephrology unit had amyloidosis and $25 \%$ of these patients were reported as phenotype II. ${ }^{9}{ }^{10}$ The clinical and family histories of these patients were not reported. On the other hand, a survey of our unit with 15 years' experience with FMF disclosed 544 patients, $7 \%$ of whom had developed amyloidosis. ${ }^{12}$ Among these there were no phenotype II patients. Similarly, Majeed et al from Jordan did not observe any phenotype II patients in their recent series of 476 cases. ${ }^{13}$

In the current study only two cases of asymptomatic proteinuria were found among the relatives of our FMF index patients. Both were older than the expected age for developing amyloidosis. None had nephrotic syndrome and in both, amyloid was negative in rectal biopsies. Proteinuria was not persistent in one of these patients and the other patient probably had a hypertensive nephropathy.

The only patient with isolated proteinuria in the JCA group, belonged to a family whose index patient had JCA and amyloidosis and who had two relatives with FMF. Several points are worth mentioning about this family. The index patient was initially considered as late onset pauciarticular JCA with polyarticular course and probable abdominal attacks of FMF. He was HLA-B27 negative and both hips were affected. Not until his sister complained of attacks of recurrent abdominal pain, was the diagnosis of JCA questioned. During the course of her disease she also developed chronic arthritis, despite continuous colchicine treatment, which resolved her abdominal attacks. Chronic arthritis is found in about 5\% of patients with FMF. ${ }^{14}$ We now think that the index case of this family either had bona fide FMF with chronic arthritis or FMF coexisting with JCA. It is interesting to observe that the only case with isolated proteinuria came from this family. Although her rectal specimen was negative for amyloid, she still carries the suspicion of phenotype II, unless otherwise proved by renal biopsy.

In this study we reasoned that the family members of patients with FMF and associated amyloidosis would be a suitable group to look for the presence of phenotype II, in that familial aggregation has been described not only for the disease itself, but also for associated amyloidosis in FMF. ${ }^{10}$ Thus we tried to assess clinically the extended families in the current study.

Another method of searching for the presence of phenotype II would have been to look for the mutant alleles on chromosome 16 that have been described in FMF. ${ }^{15}$ However, there are limitations to this approach. The genotypephenotype relations of these alleles are not yet fully understood. ${ }^{16}$ Although associations with amyloidosis in a phenotype I setting have been described, ${ }^{17} 18$ to our knowledge, no data exist for associations with isolated amyloidosis. Furthermore, up to one half of all patients with FMF have no relative with clinically apparent FMF. ${ }^{19}{ }^{20}$ Again, we are unaware of any studies related to these mutations in the family members of such probands.

In summary, even though the results of this study cannot categorically exclude the presence of phenotype II, to us they suggest that the incidence of this clinical variant is rare.

1 Sohar E, Gafni J, Pras M, Heller H. Familial Mediterranean fever: a survey of 470 cases and review of the literature. Am fever: a survey of 470 cas

2 Heller H, Sohar E, Sherf L. Familial Mediterranean fever. Arch Intern Med 1958;102:50-71.

3 Sohar E, Pras M, Heller J, Heller H. Genetics of familial Mediterranean fever (FMF), a disorder with recessive inheritance in non-Ashkenazi Jews and Armenians. Arch Intern Med 1961;107:529-38.

4 Gafni J, Ravid M, Sohar E. The role of amyloidosis in familial Mediterranean fever: a population study. Isr J Med Sci 1968;4:995-9.

5 Heller H, Sohar E, Gafni J, Heller J. Amyloidosis in familial Mediterranean fever: an independent genetically deterMediterranean fever: an independent genetically deter

6 Blum A, Gafni J, Sohar E, Shibolet S, Heller H. Amyloidosis, the sole manifestation of familial Mediterranean fever (FMF): further evidence for its genetic nature. Ann Intern Med 1962;57:795-9.

7 Zemer D, Livneh A, Pras M, Sohar E. Familial Mediterranean fever in the colchicine era: the fate of one family. Am J Med Genet 1993;43:340-4

8 Hurwich BJ, Schwartz J, Goldfarb S. Record survival of siblings with familial Mediterranean fever, phenotype 1 and 2 . Arch Intern Med 1970;125:308-11.

9 Koçak H, Beşbaş N, Saatci Ü, Bakkaloğlu A. Amyloidosis in children with familial Mediterranean fever. Turk J Pediatr 1989;31:281-7.

10 Saatci Ü, Özen S, Özdemir S, Bakkaloğlu A, Beşbaş N, Topaloğlu R, et al. Familial Mediterranean fever in children: report of a large series and discussion of the risk and prognostic factors of amyloidosis. Eur J Pediatr 1997; 156:619-23.

11 Pras M, Sohar E. Familial Mediterranean fever. In: Klippel JH, Dieppe PA, eds. Rheumatology. St Louis: Mosby, 1994: $30.1-4$.

12 Yazıc1 H, Özdoğan H. FMF in Turkey. In: Sohar E, Gafni J, Pras M, eds. Proceedings of the 1st International Conference on Familial Mediterranean fever (ferusalem, 1997). Tel Aviv: Freund, 1997:66-71.

13 Majeed HA, Rawashdeh M, El-Shanti H, Qubain H, Khuriulos N, Shahin HM. Familial Mediterranean fever in
children: the expanded clinical profile. Q J Med 1999;92: 309-18. 
14 Sneh E, Pras M, Michaeli D, Shanin N, Gafni J. Protracted arthritis in familial Mediterranean fever. Rheumatol Rehaarthritis in familial

15 International FMF Consortium. Ancient missense mutations in a new member of the RoRet gene family are likely to cause familial Mediterranean fever. Cell 1997;90:797-807.

16 Samuel J, Aksentijevich I, Torosyan Y, Centola M, Deng Z, Sood R, et al. Familial Mediterranean fever at the millennium. Clinical spectrum, ancient mutations, and a survey of 100 American referrals to the National Institutes of Health. Medicine (Baltimore) 1998;77:268-97.

17 Livneh A, Langevitz P, Shinar Y, Zaks N, Kastner DL, Pras amyloidosis of familial Mediterranean fever. Amyloid 1999;6:1-6.

18 Shohat M, Magal N, Shohat T, Chen X, Dagan T, Mimouni $\mathrm{A}$, et al. Phenotype genotype correlation in familial Mediterranean fever: evidence for an association between Met694Val and amyloidosis. Eur J Hum Genet 1999;7: 287-92.

19 Heller H, Sohar E, Sherf L. Familial Mediterranean fever. Arch Intern Med 1958;102:50-71.

20 Schwabe AD, Peters RS. Familial Mediterranean fever in Armenians. Analysis of 100 cases. Medicine (Baltimore) 1974;53:453-62. 